\title{
La pugna de los escritores del Caribe colombiano contra la vida intelectual bogotana en las publicaciones periódicas (1950-1970): adiós a la "Atenas suramericana"*
}

\author{
Paula Andrea MARÍN COLORADO \\ Universidad de Antioquia, Colombia
}

\begin{abstract}
RESUMEN
Desde sus columnas y artículos de opinión en los periódicos de Barranquilla y Cartagena, tres escritores de la Costa Atlántica: Gabriel García Márquez, Álvaro Cepeda Samudio y Héctor Rojas Herazo, iniciaron una explícita pugna contra el ámbito intelectual bogotano, por su provincianismo, anacronismo y por su falsa fama de ser la "Atenas suramericana". Cuando Gabriel García Márquez fue reconocido en el ámbito latinoamericano, como un escritor del boom, esa pugna fue legitimada en el campo literario colombiano y transformó las relaciones de poder simbólico entre estos dos subcampos regionales.
\end{abstract}

Palabras clave: prensa literaria colombiana del siglo XX, boom, Gabriel García Márquez, Álvaro Cepeda Samudio, Héctor Rojas Herazo.

The fight of the writers from the Colombian Caribbean against the intellectual environment of Bogotá in the periodical publishing (1950-1970):

Farewell to the "Atenas suramericana"

\begin{abstract}
From their columns and articles for the newspapers in Barranquilla and Cartagena, three writers from the Atlantic Coast: Gabriel García Márquez, Álvaro Cepeda Samudio and Héctor Rojas Herazo, began a fight directly against the intellectual environment of Bogotá. According to these writers, it was anachronistic, full of "local color" and its fame of being the "Atenas suramericana" was false. When Gabriel García Márquez was recognized in Latin America as a writer of the boom, that fight was legitimated inside the Colombian

* Este artículo se deriva de la investigación El crítico de lo cultural en las publicaciones periódicas de 1900 a 1960. Una forma histórica del intelectual colombiano (2013-2016), ejecutado con recursos de la Convocatoria de proyectos de investigación de Ciencias Sociales, Humanidades y Artes 2012, financiada por el Comité para el Desarrollo de la Investigación (CODI) de la Universidad de Antioquia; también se inscribe en el marco de la Estrategia de Sostenibilidad para grupos de investigación CODI 2013-2014.
\end{abstract}


literary field and this fact renovated the symbolic power relations between these regional subfields.

Key words: Colombian literary press from $20^{\text {th }}$ century, Boom, Gabriel García Márquez, Álvaro Cepeda Samudio, Héctor Rojas Herazo.

SUMARIO: 1. Introducción. 2. Bogotá y el Caribe colombiano: de la "Atenas suramericana" a la "poesía testicular". 3. El boom y la autonomía cultural latinoamericana: el insoslayable García Márquez. 4. Conclusión: la literatura, la política, la "moral".

\section{Introducción}

Para la historia de la literatura colombiana, es un hecho incuestionable que Gabriel García Márquez fue el primer escritor que logró insertarse en un fenómeno literario latinoamericano y luego internacional (el boom), de una manera mucho más continua y contundente de la que ya lo habían hecho José Eustasio Rivera con La vorágine (1924) y Jorge Isaacs con María (1867); asimismo, el fenómeno editorial que desata Cien años de soledad en Latinoamérica se convierte en un imperativo para pensar de una nueva forma la industria editorial colombiana. Este hecho no es sólo resultado de las circunstancias de la literatura en el continente, sino del gran trabajo de crítica y divulgación hecho por el mismo García Márquez y por Álvaro Cepeda Samudio acerca de la necesidad de insertar la literatura colombiana en el ámbito internacional, de escribir una literatura con valores universales, prescindiendo del "color local" -y en ese trabajo la adopción de la figura de Faulkner como un escritor latinoamericano, porque era del Caribe (García Márquez y Vargas Llosa, [1967]: 53), fue fundamental-. ${ }^{1}$ El reconocimiento de la literatura garcíamarquiana saca de circulación la imagen de la "Atenas suramericana", desplaza considerablemente a Bogotá como centro "representativo" del país, y muestra una imagen de Colombia desde una región poco reconocida como eje de la vida intelectual: el Caribe. La aceptación casi inmediata de la crítica y del público lector hace que la figura de García Márquez inaugure un nuevo momento del campo literario colombiano. ${ }^{2}$

${ }^{1}$ Según Ángel Rama, sería también un reflejo de las imposiciones de la economía mundial, de la internacionalización de sus procesos (Rama, 1985: 81). Sobre este punto podría pensarse que, al ser Barranquilla una ciudad reconocida, sobre todo, por su vida comercial, era más fácil que sus escritores se percataran de esta necesidad de internacionalización de la literatura, no, claro, desde su aspecto netamente económico, sino viendo las ventajas de salir del provincianismo y del anacronismo de las "letras nacionales".

2 Pierre Bourdieu explica que el campo intelectual es un espacio de "luchas" por la obtención del capital simbólico y su legitimación, y por la apropiación de los bienes culturales; tales "luchas" son entendidas como "las relaciones objetivas que se dan entre las 
A partir de la década de 1950, la imagen de la "Atenas suramericana" se empieza a cuestionar; de esto dan cuenta los diversos artículos publicados en los suplementos literarios de El Tiempo y de El Espectador (periódicos de alta circulación en el país) y las constantes críticas publicadas en la prensa de Barranquilla, Cartagena y Bogotá, elaboradas por quienes serían los protagonistas de las mayores rupturas narrativas de mitad de siglo XX en Colombia: Héctor Rojas Herazo, Cepeda Samudio y García Márquez. El desmonte de la imagen de Bogotá como capital de las letras colombianas incluyó la validación de una nueva imagen de escritor (y del uso del lenguaje) y de una nueva actitud ante la realidad reelaborada en la obra literaria, a partir de la experiencia que los tres escritores costeños (sobre todo, Cepeda y García Márquez) habían tenido con el periodismo.

Estos escritores concretaron las tareas de modernización literaria que se habían trazado los escritores del grupo Los Nuevos en 1925, quienes, en su mayoría, fungieron como funcionarios públicos en los gobiernos de la República Liberal (1930-1946): legitimaron una nueva función política para el escritor, definieron una forma de profesionalización para el escritor, fuera de las prebendas del Estado, y afirmaron la autonomía de la literatura frente a los partidos políticos y a la intervención de la Iglesia Católica. Estos logros se insertaron en el momento que atravesaba el sistema literario latinoamericano y las condiciones favorables que presentaba para el afianzamiento de un género como la novela y la legitimación de una autonomía cultural latinoamericana, gracias, en gran parte, a la consolidación de una "familia intelectual" (Gilman, 2003) integrada en torno a la Revolución Cubana.

\section{Bogotá y el Caribe colombiano: de la "Atenas suramericana" a la "poesía testicular"}

Sobre la denominación de "Atenas suramericana" para Bogotá, por sus diversas señales de tener una rica vida intelectual, se pueden mencionar las referencias de Miguel Cané en su libro Memorias de viaje (1884), la de Marcelino Menéndez Pelayo en Antología de la poesía latinoamericana (1892) y la de Pierre d'Espagnat en 1898 (Zambrano, 2002: 9). Pese a ellas, a estas alturas de la historia de la expresión, aún no resulta muy claro su origen ni cómo se propagó en el ambiente capitalino y nacional como una verdad aceptada por la élite letrada. En cambio, sí resulta evidente que esta denominación vino a sellar la autodefinición acerca de la "tradición humanística" colombiana y, especialmente, bogotana. Esa tradición se

posiciones relativas que los agentes ocupan en él [el campo intelectual], es decir, la estructura que determina la forma de las interacciones" (1997: 272).

El campo intelectual y, específicamente, el literario, se define, entonces, en función del sistema de posiciones que ocupan los agentes, concebidos como "operador[es] práctico[s] de construcciones de lo real" (Bourdieu, 1997: 269). 
apoyaba en la fama que tenían (dentro y fuera del país) Miguel Antonio Caro y Rufino José Cuervo como representantes y defensores del conocimiento sobre las culturas antiguas y sobre el buen uso del castellano.

La exhibición de conocimientos sobre las culturas griega y romana antiguas y el hecho de ser un buen conversador (tener claras las reglas de la conversación y hacer buen uso del lenguaje) se convirtieron en índices de distinción social, sobre todo, en la sociedad bogotana, y desde allí se trasladaron a las diversas regiones del país como signos de prestigio. Fabio Zambrano recalca lo más interesante de este hecho del siguiente modo:

En ese momento, finales del siglo XIX y primeras décadas del XX, Bogotá atravesaba por la peor crisis higiénica de toda su historia y la densificación de la ciudad obligaba a ricos y pobres a vivir dentro del mismo espacio urbano, inclusive a compartir las mismas casas, en razón del empobrecimiento general que vivía la ciudad. En esta situación de la ciudad, donde los pocos símbolos de jerarquización social del espacio urbano se habían perdido, la élite recurre al buen hablar, los buenos modales y el manejo de un protocolo social, como fronteras entre lo que ellos consideran la civilización, su cultura, y la barbarie, la del "pueblo bajo" y de los provincianos (Zambrano, 2002: 10).

Es decir que estos símbolos de distinción social se instauraron ante la amenaza de la pérdida de las jerarquías sociales en la Bogotá de principios de siglo XX y se practicaron en los salones: círculos exclusivos que necesitaban de un "consenso de cristal entre sus miembros" (Jaramillo, 1997: 85), un acuerdo que nadie ponía en duda, que todos aceptaban con la promesa de seguir perteneciendo a ellos. ${ }^{3}$ De esta manera, se comprende la legitimación de los denominados "gramáticos" para ocupar altos cargos dentro del Estado durante casi todo el siglo XIX y comienzos del XX en Colombia, y la instauración de la literatura como la máxima expresión artística, pues ambas prácticas evidenciaban el buen uso del castellano.

La presencia de una tradición filosófica en la cultura clásica amenazaba el imperio de la Iglesia Católica sobre las mentes de los colombianos; había que buscar una manera de convencer a las élites de que la filosofía -la razón-solicitaba "el auxilio de la revelación sobrenatural" (Forero, 1950: 278). De esta manera quedaba sellado el pacto entre los miembros exclusivos de la élite letrada: Bogotá era la "Atenas suramericana" porque teníamos personajes conocedores de la cultura clásica, porque hablábamos un excelente castellano y porque, con su arribo al Nuevo Mundo y, específicamente, a Bogotá, esa cultura se "purificaba" por la

${ }^{3}$ Sobre el "arte de la conversación", J. Eduardo Jaramillo Zuluaga (1997) recuerda las Lecciones de urbanidad (1886) de José Manuel Marroquín y el Manual de urbanidad y buenas maneras (¿1854?) de Manuel Antonio Carreño como textos que ayudaron a afianzar la importancia de esta práctica como signo de distinción social. 
presencia de la doctrina cristiana (Félix Restrepo, S. J., citado por Forero, 1950: 277): "Las manifestaciones de arte auténtico, principalmente en el campo literario, nacidas en el ambiente bogotano, revisten [...] las características generales de este aticismo" (Forero, 1950: 277). ${ }^{4}$ Así, la famosa "tradición humanística" se convirtió en un código estético que permeó la producción cultural de los intelectuales de la primera mitad del siglo XX en Colombia: los escritores debían exhibir ese "buen decir" y expresar, a través de ese buen uso del castellano, la pureza de sus ideas y sentimientos, que no podía provenir de algo diferente a la moral cristiana.

Alejándose de esta tradición, algunos escritores, artistas y periodistas del Caribe se pusieron en la tarea de difundir la cultura de su región desde finales de la década de 1940. Artículos publicados en la prensa por Héctor Rojas Herazo, Gabriel García Márquez y los trabajos de investigación sobre el folclor caribeño realizados por Manuel Zapata Olivella (García Usta, 2003; Gilard, [1981] 1997) empezaron a mostrar la riqueza cultural de una región que, ante los ojos de la "Atenas suramericana", siempre había sido inferior intelectualmente. Paralelamente, para 1951, el Suplemento Literario del periódico bogotano El Tiempo inició una encuesta entre algunos intelectuales bogotanos acerca del siguiente interrogante: "¿Somos, en realidad, la llamada Atenas Suramericana? O por el contrario, ¿el país soporta desde hace rato el colapso de su predominio intelectual en el continente?" (edición del 22 de abril de 1951, p. 1).

Esta pregunta es contestada por José María Restrepo Millán y por Hernando Téllez; en sus respuestas es visible la diferencia entre el tipo de intelectual que creía en esa imagen de ciudad-cultura y aquel que podía ya ponerla en entredicho. La visión de Restrepo Millán se relaciona con la de otros intelectuales de la época, quienes se muestran preocupados por la "decadencia" de la fama de este estatuto intelectual para la capital del país: "Me parece que el ambiente principió a enrarecérseles a las humanidades en Colombia por allá durante el segundo decenio de este siglo" (Restrepo M., 1951: 1). Restrepo Millán establecía así una relación inversamente proporcional entre la modernización del país y su desarrollo intelectual, pues es a partir de esta segunda década (y más aún desde la tercera) que empiezan a ser más visibles las reformas modernizadoras en la capital colombiana: "Las llamadas humanidades modernas y las demás que pudieran inventarse, no son propiamente tales" (Restrepo M., 1951: 1). Había, pues, una negación hacia ampliar la perspectiva acerca de lo que se concebía como humanismo, pues la élite letrada de la capital y del país sentía amenazada su preeminencia social. Esta es la causa para que se empiece a hablar del "imperio de la banalidad" y de la "desmoralización intelectual" (Meluk, 1952: 10) en la sociedad bogotana.

4 Sus características generales eran pureza, corrección, sencillez, elegancia, gusto acendrado y, en general, perfecta euritmia (Forero, 1950: 276). 
La crítica frente a esta actitud la demuestra Hernando Téllez cuando afirma: "El humanismo en Colombia no ha sido jamás, en ningún momento de la historia del país, una tradición. [...] La cultura humanística es en Colombia un privilegio excepcional" (Téllez, 1951: 3). El hecho de que la intelectualidad colombiana pudiera jactarse del prestigio internacional de los trabajos filológicos realizados por Caro y por Cuervo no hacía más que evidenciar la distancia cultural tan abismal que existía entre la élite letrada y las demás capas de la sociedad: "El sesenta por ciento de los colombianos no ha recibido todavía el [...] alfabeto y del cuarenta por ciento restante, la mitad por lo menos no se halla [...] en condiciones económicas de concluir las disciplinas de la segunda enseñanza" (Téllez, 1951: 3). Los argumentos de Téllez constituían una dura crítica a los esgrimidos por Restrepo Millán, Meluk y Forero Ruíz (citado arriba) acerca de nuestra "amplia" tradición humanística; para Téllez, era hora de pensar en un "humanismo verdadero" que disminuyera las diferencias sociales $-\mathrm{y}$ ahora también económicas-, no que siguiera insistiendo en ellas para mantener privilegios de viejas castas letradas que ahora nada tenían que decir frente a las cada vez más duras realidades del país.

En 1962, el director de la Academia Colombiana de la Lengua, el sacerdote jesuita Félix Restrepo, seguía empecinado en defender el título de "Atenas suramericana" para Bogotá: "Hemos querido que nuestro edificio [donde funcionaba la Academia] sea un verdadero monumento al castellano imperial; por eso su arquitectura es noble y su decoración, sin ser lujosa, será suficientemente digna para que Bogotá siga mereciendo el nombre de Atenas Suramericana" (Restrepo entrevistado por García Niño, 1962: 1). En esta misma entrevista para Lecturas Dominicales de El Tiempo, ${ }^{5}$ Restrepo afirmaba que la labor del escritor en torno al idioma era "atenerse a las normas tradicionales, por lo que hace a la sintaxis, y dar rienda suelta a la imaginación en lo relacionado con el vocabulario" (Restrepo entrevistado por García Niño, 1962: 1), es decir, se pensaba que un organismo como la Academia debía seguir imponiendo reglas para la creación literaria.

Barranquilla había tenido, primero que Bogotá, servicio de teléfono, luz eléctrica, acueducto, emisora de radio y compañía de aviación (Gilard, 1984: 909); estos avances tecnológicos no se encontraban al mismo nivel del prestigio de la cultura letrada ostentada por la capital colombiana que, para su élite, estaba por encima de cualquier tipo de desarrollo alcanzado a través de procesos de modernización. Sin embargo, Cepeda Samudio, Rojas Herazo y García Márquez empezaron a cuestionar, precisamente, esta jerarquía de valores:

${ }^{5}$ El Suplemento Literario de El Tiempo había pasado a llamarse Lecturas Dominicales desde 1954 (ya había tenido este título en la década de 1920). 
Porque nosotros, los de "provincia", no tenemos noticia alguna de los movimientos literarios y artísticos de los guardadores de nuestras tradiciones culturales $[\ldots]$.

De una frase cursi, dicha por decir algo más que por calificar una sociedad que comparaba a Bogotá con Atenas, se ha construido un falso concepto del desarrollo de la cultura del país [...].

¿Cómo podemos pedir que se nos tenga en cuenta si en Colombia no se publica un libro de valor internacional? (Cepeda, 2001: 153).

Es claro el tono irónico empleado por Cepeda Samudio. Él sabía que a los ojos de los intelectuales capitalinos, ellos - lo de la Costa Atlántica- eran los "provincianos", pero a partir de su conciencia sobre las diferencias de poder simbólico entre ambos subcampos de producción cultural en Colombia, lanza su crítica contra unos valores que cree infundados: Bogotá no tiene movimientos literarios o artísticos de calidad, su comparación con Atenas es sólo una frase cursi y no hay autores con valor internacional. Para Cepeda, Rojas H. y García M., la "provincia" era más cosmopolita que la misma capital del país.

Los resultados de un concurso de pintura llevado a cabo en Barranquilla en 1955, al que habían sido invitados jurados traídos de la capital colombiana, son el punto de partida aprovechado por García Márquez para evidenciar las diferencias entre la cultura de la Costa Atlántica y la andina, en un artículo publicado en $E l$ Espectador (Bogotá, 22 de enero de 1955). El concurso, finalmente, había sido ganado por Ignacio Gómez Jaramillo, pero los datos que presenta García M. dan cuenta de que el fallo del jurado había sido alterado para privilegiar a un artista del interior del país y no a alguno de los tres pintores más opcionados (todos costeños): Alejandro Obregón, Enrique Grau y Cecilia Porras. En este punto se pregunta García M.:

¿Se habrá extendido éste [el centralismo] hasta las regiones que consideramos inmunes a esta clase de influencias, intrigas y procederes poco conocidos en nuestro medio, sincero, espontáneo y franco?

[...] El público era partidario de favorecer un cuadro de Alejandro Obregón, abstracto, antes que el de Gómez Jaramillo, puramente figurativo y anecdótico (García M., [1955] 1997: 305).

El fallo de los jurados le sirve a García M. no sólo para evidenciar diferencias de tipo sociológico entre regiones, sino de tipo artístico: el ambiente de la Costa Atlántica era más propicio para alentar propuestas artísticas más modernas que el de la capital colombiana -anclada aún en el criterio de que la pintura debía ser anecdótica-, pues los costeños no tenían los "vicios" que atacaban el sano funcionamiento de la vida intelectual capitalina (la falsedad, la simulación y el artificio). 
Por su parte, Rojas H. afirmaba en el periódico El Universal (Cartagena), en 1951:

Si tiene, en realidad, Colombia una tradición humanística de qué ufanarse, dónde comienza esa tradición y quiénes, vinculados al progreso de nuestra cultura, la representan actualmente [...]. Ya estamos hartos de ver a los que en el altiplano pautan el interés de este país y señalan las reglas del juego (Rojas H., [1951a] 2003: 357)

Rojas H. señalaba abiertamente la necesidad de que hubiera una transformación en el funcionamiento de las estrategias de reconocimiento y posicionamiento de los escritores en el campo literario colombiano. Ni este tono ni esta forma directa de decir las cosas habían aparecido antes en la prensa capitalina. Se podrían mencionar los casos aislados de Hernando Téllez y de Eduardo y Jorge Zalamea Borda (escritores admirados por los costeños), pero el cambio de este momento del campo literario consiste en que se empieza a elevar una voz continua y más o menos consolidada por un grupo de escritores (que se ha denominado como el Grupo de Barranquilla) provenientes de una "provincia", quienes cuestionan la validez de las normas y los valores estéticos legitimados por la élite letrada capitalina.

Cepeda, Rojas H. y García M. lucharon, desde sus columnas y artículos de opinión, para legitimar una nueva literatura y una nueva imagen de escritor. En medio de toda la relevancia de este proceso para lograr una modernización -que había comenzado desde finales del siglo XIX- definitiva de la literatura colombiana, se destaca la crítica que realizaron al mandato impuesto desde la Academia Colombiana de la Lengua sobre el uso del lenguaje en la literatura. En una columna de 1952 (9 de septiembre, El Heraldo -Barranquilla-), García M. llega a definirse a sí mismo como un escritor que "ignora las actuales reglas de ortografía" y a aseverar que lo que se necesita en este aspecto es "la anarquía" (García M., [1952a] 1997: 581); por su parte, Rojas H., en un artículo de 1950, publicado en El Universal, se refería a la gramática como "carpintería" de la escritura (Rojas H., [1950a] 2003: 344), y en otro del mismo año y del mismo periódico, se quejaba de que la Academia de la Lengua quisiera convertir el castellano en una "momia de museo", al dejarlo en manos solamente de lo que satisficiera a los gramáticos e impedir su renovación a partir del uso de los hablantes cotidianos (Rojas H., [1950b] 2003: 345-346).

Según estos escritores, escribir bien no dependía de la habilidad para exhibir las normas dictadas por la Academia de la Lengua; al contrario, la literatura exigía separarse de este mandato para vincular la anarquía y el lenguaje cotidiano en sus 
formas. ${ }^{6}$ Según, Cepeda, los bogotanos no sabían escribir: "Los diálogos [eran] falsos y las descripciones alambicadas, llenas de lugares comunes que ya eran comunes hace cincuenta años" (Cepeda, [1961c] 2001: 164). ${ }^{7}$ La renovación del lenguaje, de su uso, basado en la libertad del escritor, conllevaba la posibilidad de cuestionar estos lugares comunes, las verdades aceptadas tanto en la forma artística como en la realidad social (García M., [1952c] 1997: 576 -30 de agosto de 1952, El Heraldo-). Para Cepeda, Rojas H. y García M., el periodismo fue la forma de relacionarse con el lenguaje de una manera diferente, de experimentar con él y encontrar un estilo singular, pero también de señalar un punto de vista propio frente a la realidad colombiana e internacional: "Escarbar y descubrir lo que hay detrás del hecho diario" (Cepeda, [1966] 2001: 162).

Para estos tres escritores, la misma Academia Colombiana de la Lengua era un lugar que alentaba la evasión de la realidad y la actitud de dar la espalda a los problemas que en la década de 1950 azotaron la sociedad colombiana y, sobre todo, el centro del país: la denominada Violencia. ${ }^{8}$ En un artículo de 1952 (28 de agosto, El Heraldo), García M., sutilmente, se burla de la actitud de Luis López de Mesa (miembro de la Academia, esa "cosa intemporal y extraordinaria") durante una entrevista realizada por un colega suyo:

Ante la pregunta del periodista acerca de la situación política del país, López de Mesa contestó: Mi tesis, ya usted la conoce: los partidos en la oposición tienen que aprender gramática [...].

Sería una estimulante labor de las comisiones unitivas, ésa de dirigirse a los Llanos Orientales no ya con el incómodo lastre de los fusiles y las municiones, sino con un instructivo cargamento de textos gramaticales, para repartirlos generosa y patrióticamente entre los bandoleros (García M., [1952b] 1997: 576).

La actitud reticente de la Academia frente a las demandas para la renovación de las reglas gramaticales, teniendo en cuenta el uso cotidiano de los hablantes -el

\footnotetext{
${ }^{6}$ Los artículos del novelista español (radicado en Bogotá) Clemente Airó, publicados en Espiral (la revista bogotana que él dirigía), también dan cuenta de esta actitud crítica: "Un novelista no es un académico de la lengua" (Airó, 1962: 9).

${ }^{7} \mathrm{Y}$ esa crítica hacia la "pésima" forma de escribir de los bogotanos era reafirmada por los artículos en donde cada uno de ellos validaba al otro como el "primer cuentista / novelista nacional" o como "verdadero poeta" (García M. a Rojas H.; Rojas H. a García M. y a Cepeda; Cepeda a García M.).

${ }^{8}$ Desde el segundo lustro de 1930, se manifestaron los primeros brotes de violencia armada entre liberales y conservadores en las áreas rurales colombianas. Este enfrentamiento se hacía visible también en las intervenciones públicas de algunos políticos de ambos partidos y en varias publicaciones periódicas de la época. Tras el asesinato de Jorge Eliécer Gaitán en Bogotá, en 1948, los actos de violencia se recrudecen y generalizan. Es a esta última etapa de este período de la historia de Colombia que hago referencia aquí.
} 
"vulgo"-, se reflejaba también en su actitud frente a la realidad del país y en su igual reticencia para transformar las dinámicas culturales y las jerarquías sociales. Los partidos en la oposición, en ese momento, eran los liberales, es decir que López de Mesa estaba criticando la forma en la que éstos usaban el lenguaje -e, implícitamente, también su forma de actuación-. Recordemos que López de M. pertenecía a la generación del Centenario (1910), una generación, en su mayoría, conservadora y fuertemente marcada aún por la imagen de la "Atenas suramericana". La generación del Centenario fue duramente cuestionada por la de Los Nuevos (1925) y los intelectuales pertenecientes a esta fueron llamados luego por los distintos gobiernos de la República Liberal (1930-1946) para cumplir funciones públicas dentro de sus distintos Ministerios; los gobiernos liberales, entonces, apoyaban las reformas -tanto en el ámbito político como en el culturalimpulsadas por estos intelectuales "nuevos", pero cuando el partido Conservador retoma el poder en 1946, estas reformas y sus gestores sufren un fuerte período de regresión y represión. Cepeda, Rojas H. y García M. reiteran las críticas que, de alguna manera, ya habían sido enunciadas por Los Nuevos, pero su distancia física y mental de las prácticas intelectuales bogotanas les permitía enfatizar en aspectos en los que Los Nuevos, por su cercanía a las lógicas de funcionamiento de ese campo literario y al gobierno de turno, no podían. ${ }^{9}$

Los Nuevos legitimaron un nuevo tipo de intelectual: el proveniente ya no de las élites del país, sino de la emergente clase media (Loaiza Cano, 1995: 75). En este grupo social se encontraba la mayoría de los funcionarios públicos $-\mathrm{y}$, por ende, una buena cantidad de intelectuales al servicio del Estado- y había venido consolidándose, en parte, a partir de su diferencia con la clase obrera; Ricardo López explica cómo

en 1936 y 1939 se discutieron y publicaron normas con respecto a la carrera administrativa de los empleados públicos estatales. Las disposiciones del

${ }^{9}$ Gilard explica cómo ese distanciamiento de las prácticas intelectuales bogotanas se evidencia en su negación a escribir en los suplementos literarios de El Espectador y de El Tiempo, en no escribir ensayos sino artículos de opinión (ir en contra de la "pose" del intelectual tradicional del momento) y en validar la literatura contemporánea norteamericana e inglesa (William Faulkner, Ernest Hemingway, Virginia Woolf) por encima de las expresiones literarias colombianas consideradas como autóctonas (las de los denominados "Greco-caldenses"). (Gilard, 1984: 911).

En relación con la cercanía ideológica entre García M., Rojas H. y Cepeda con Los Nuevos y, en general, con los primeros gobiernos de la República Liberal, se puede revisar un artículo de García Márquez, publicado en 1960 (Acción Liberal, 1), en donde es clara su empatía con el gobierno de Alfonso López, quien deseaba "sacar a Colombia del desván histórico en que se encontraba y ponerla de un salto en el siglo XX" (García M., [1960a] 1997: 569). 
gobierno municipal [...] dibujaron cuidadosamente la diferencia entre "aquellos que trabajan en fábricas y aquellos que trabajan en oficinas" [...].

Esta nueva reglamentación sólo buscaba que el "mérito fuera el único indicador para avanzar" en la burocracia estatal. Este mérito [...] debía poner a estos empleados de clase media, vistos como decentes, bien preparados y varoniles, al frente de estas tareas estatales que hasta entonces habían sido monopolizadas por unas “oligarquías” (López, 2011: 93-94).

Estos hechos demuestran cómo la educación y no "los privilegios de cuna" se iba convirtiendo en garantía para escalar una posición social para aquellos nuevos hombres que afianzaban su lugar en la escena capitalina: los oficinistas, y para separar las actividades intelectuales de las manuales, realizadas por los obreros. ${ }^{10}$ Pese a la validación de este nuevo tipo de distinción simbólica en las décadas de 1920 y 1930, las palabras de López de Mesa insistían en la superioridad de los conservadores (tradicionalmente, relacionados con la élite letrada del país) para usar bien el lenguaje -y comportarse correctamente-. Así, pues, la persistencia de prácticas anacrónicas en los letrados capitalinos hace que Cepeda, Rojas H. y García M. asuman una actitud combativa frente a la Academia, al lenguaje, a la literatura y a la realidad misma. ${ }^{11}$

${ }^{10}$ Estos nuevos trabajadores (oficinistas, empleados públicos, periodistas, intelectuales) validaron un nuevo espacio de sociabilidad: los cafés. A diferencia de los salones, los cafés se proponían como un espacio más democratizado, pero, al igual que en ellos, había prácticas establecidas de exclusión y reconocimiento -por ejemplo, dejar sentar o no a alguien en una mesa- (Monje Pulido, 2011: 131-133).

${ }^{11}$ Esta actitud combativa también les ayudaba a defenderse de los ataques que les hacían desde revistas como la bogotana Letras Nacionales (1965-1985), dirigida por Manuel Zapata Olivella. En sus artículos críticos, la revista privilegiaba a escritores como José Antonio Osorio Lizarazo, Manuel Mejía Vallejo, Eduardo Caballero Calderón y Manuel Zapata Olivella, es decir, autores en quienes la toma de posición social y/o regionalista era fácilmente discernible por su -según los críticos- cercanía a cierto tipo de realismo. Para los redactores, esta toma de posición era necesaria para consolidar una literatura "nacional", no aquella que se acercaba a las tendencias estéticas de vanguardia, como era el caso de la de Cepeda S., Rojas H. y García M.

Pese a estos ataques, es necesario mencionar que una revista tan importante para la vida intelectual colombiana como la también bogotana Mito (1955-1962), fundada por Jorge Gaitán Durán y Hernando Valencia Goelkel, fue una plataforma fundamental para la difusión y reconocimiento de las obras de García M., Cepeda S. y Rojas H. Una parte de lo que luego se publicaría bajo el título de La casa grande apareció en los números 22 y 23 (1958-1959); El coronel no tiene quien le escriba, de García M., se publicó en el número 19 (1958); y poemas de Rojas H. aparecieron en los números 5, 22 y 23 (1955-1956, 19581959). 
De esta actitud surge la imagen del escritor como un hombre para quien la experiencia vital y la intelectual tenían la misma importancia en el trabajo de creación literaria. Así lo demuestra la admiración que expresa García M. cuando Faulkner declara en una entrevista: "Yo no soy un hombre de letras. Yo soy un granjero a quien le gusta contar historias" (Faulkner citado por García M., [1951] 1997: 400 -15 de enero, El Heraldo-); asimismo, Rojas H. expresa su beneplácito (en un artículo publicado en el Diario de Colombia) por la actitud de Cepeda Samudio: "Para él es exactamente lo mismo tomarse un vaso de cerveza, abrazar una muchacha, mirar su caballo, leer un libro o ponerse a conversar con un niño [...]. Por eso es un poeta" (Rojas H., [1954] 2003: 175). Este nuevo escritor, pues, no evadía su experiencia inmediata, cotidiana, y se había quitado el hálito trascendental -inspirado por la "musa"- que exhalaban los escritores de la capital, su apego a las "buenas maneras" y al estudio de la retórica y la oratoria:

Se le perdonará a George Lee Bieswell Cotes el error fundamental de publicar un libro cuando todavía no se ha dejado de ser un excelente, un extraordinario estudiante de retórica. Claro que no me refiero a la retórica como disciplina mental, sino a la retórica práctica, ampulosa, asfixiante y barata. [...]

[Estoy seguro de que este escritor reconocerá] los inconvenientes que, para la perfecta realización de su obra, constituyeron la grandilocuencia, el exagerado sentido onomatopéyico, la frondosidad discursiva (García M., 1949: 5-6).

Esta cita pertenece al prólogo que García Márquez escribió para la novela Neblina azul. En él no sólo es visible su crítica a la retórica (al uso artificial del lenguaje), sino también un distanciamiento frente a lo que él consideraba la vida intelectual capitalina: los prólogos no tenían que ser un compendio de elogios para el autor -como era ya costumbre-; debían ser un ejercicio que evidenciara la franqueza y la responsabilidad intelectual de quien los escribía.

Este momento del campo literario colombiano se configura, entonces, como el primero en el que los espacios intelectual y cotidiano no se perciben como contrarios para el quehacer de la literatura -aunque aún se mantienen los límites entre la "alta cultura" y la cultura "popular"- y en el que el escritor se siente responsable de su realidad, de su presente, fuera del ámbito político más oficial (liberal o conservador), como se había entendido hasta entonces: "Castro Saavedra rescata la poesía de la evasión [...]. Poesía testicular para resistir a la diaria embestida de la muerte" (García M., [1950] 1997: 135 -El Heraldo, 4 de marzo-). ${ }^{12}$ A diferencia de "los escritores [que] se habían refugiado en una fortaleza de especulaciones filosóficas y averiguaciones humanísticas" (García M., [1960b] 1997: 578 -Acción Liberal, 2-), la imagen del escritor propuesta por García M.,

${ }^{12}$ El concepto de "poesía" se amplía en esta década; ya no sólo es una definición para el “arte de versificar", sino una cualidad de la obra literaria verdadera (Airó, 1962: 13). 
Cepeda y Rojas H. proponía su función en constante "contacto con la vida cotidiana, que es la única realidad del hombre" (Cepeda, [1961b] 2001: 165; Rojas H., [1956] 2003: 248 -Diario de Colombia-). Esta creencia fue la base desde la cual estos tres escritores concibieron cuentos y novelas alejados tanto de la visión idílica de las novelas sentimentales y regionalistas más aceptadas dentro de la mayoría del público lector (minoritario, en todo caso, para esta época), como -más adelante- de la llamada literatura de la Violencia.

La literatura "testicular" invita a hablar acerca de "lo que hemos ganado y lo que hemos perdido frente a la muerte" (Rojas H., [1951b] 2003: 353 -Revista Universidad de Antioquia-), no sólo de los muertos, como solía hacerse en la mayoría de novelas de la Violencia. A García Márquez le preocupaba "la gente que era masacrada, pero también el policía que llegaba al pueblo a masacrar" (García M. y Vargas Ll., [1967] s.f.: 50), los motivos que había tenido para hacerlo y los sobrevivientes. Las novelas Respirando el verano (1962, Héctor Rojas H.), La casa grande (1962, Álvaro Cepeda S.) y La mala hora (1962, Gabriel García M.) dan cuenta de esta nueva forma de narrar la Violencia colombiana -a la que habría que agradecerle que hubiera despertado a los escritores ante la realidad del país (García M., [1960b] 1997: 578 -Acción Liberal, 2-)-: mirando el mayor número de perspectivas sobre los hechos, sus causas y consecuencias en la sociedad colombiana y, sobre todo, aquello que tenía de fenómeno universal, no solamente local; de allí que su centro de atención sea el "hombre", no un partido político, una clase social o una idea moral o filosófica (Airó, 1965: 4; Rojas H., [1962] 2003: 274 -Boletín Cultural y Bibliográfico del Banco de la República-). De esta manera, la literatura colombiana y, específicamente, la novela, fue alcanzando validez en el ámbito latinoamericano, sobre todo, con la siguiente novela de Gabriel García Márquez: Cien años de soledad (1967), publicada en Buenos Aires.

\section{El boom y la autonomía cultural latinoamericana: el insoslayable García Márquez}

Para el caso de la literatura latinoamericana, el problema de la autonomización del campo literario está estrechamente relacionado con el problema de la afirmación de la autonomía cultural del continente:

\footnotetext{
La autonomía literaria americana había sido propuesta inicialmente (neoclásicos) como un proyecto de la élite culta para los cuadros intelectuales y administrativos y había sido ampliada posteriormente (los románticos) como un proyecto de la élite europeizada para remodelar poblaciones enteras. La palabra "pueblo" estaba en todas las bocas pero en esas bocas no era el pueblo el que hablaba y nada lo prueba mejor que la escasísima difusión de los productos literarios de ambas élites. El robustecimiento de tal autonomía literaria sólo podía pasar por la ampliación de su base, es decir, por la participación de vastas masas en la emisión y recepción de mensajes literarios (Rama, 1985: 73).
} 
La búsqueda de la afirmación de la autonomía artística y la de la autonomía cultural definen las dicotomías que orientan las tomas de posición principales en la historia de la literatura latinoamericana desde la Colonia y hasta el boom: estética pura-modernista-vanguardista-formalista-universalista-cosmopolita ${ }^{13} /$ arte costumbrista-social-americanista-autóctono-realista-nacionalista-comprometidoregionalista. El boom de la novela latinoamericana se revela como el encuentro entre la autonomía literaria y la cultural, y entre un amplio público lector y los escritores: la ansiada "ampliación de su base"; sin embargo, es necesario recordar que los autores que abanderaron este fenómeno del campo literario (García Márquez, Julio Cortázar, Mario Vargas Llosa y Carlos Fuentes) siempre defendieron en sus discursos sociales escritos y orales la necesidad de ver la literatura como un acto de libertad no comprometido con ningún partido político, ninguna idea de patria o nacionalidad y con ninguna ideología (pese al apoyo directo de los tres primeros -en un primer momento- al gobierno de la Revolución Cubana).

Para el caso de Colombia, la tendencia hacia la novela "americana" es mayor que hacia las propuestas estéticas vanguardistas entre las décadas del treinta y el cincuenta (Marín, 2013); en la década del sesenta, la propuesta de una novela social será aceptada por una buena parte de la crítica literaria y se relacionará con la tendencia del arte comprometido y de la estética marxista, propias de la coyuntura ideológica producida por el fenómeno de la Violencia y de la Revolución Cubana. Desde finales de la década del sesenta, con la consagración de Gabriel García Márquez en el campo literario, la función del arte dejará de estar asociada tanto a un preciosismo propio de la estética clásica, tradicional (la leyenda de la "Atenas suramericana"), como a un compromiso político o ideológico.

Gabriel García Márquez debía su prestigio en Colombia al periodismo más que a la literatura, hasta 1961 (Gilard, [1982] 1997: 65), año en el que gana el Premio Esso de Novela por La mala hora; la reedición de su novela La hojarasca en 1959 para el I Festival del Libro Colombiano también le había traído reconocimiento, pues fue el más joven de los autores reeditados (Gilard [1983] 1997: 53). El número de artículos publicados en las revistas culturales colombianas entre 1963 y 1975 sobre la obra de Gabriel García Márquez, realizados por críticos que hoy constituyen una referencia insoslayable para quienes desean abordar las creaciones del Nobel colombiano (Volkening, Maturo, Jitrik, Ludmer, Rama), demuestran que, con la consagración de García Márquez en Latinoamérica y en Europa, este escritor deja de ser un "costeño", "provinciano", para convertirse en un colombiano y, luego, en un latinoamericano. Su obra se convierte en la consagración del arte autónomo (estética y culturalmente), ya que se opone directamente a la tradición

${ }^{13}$ Me refiero a "modernista" no sólo como el movimiento literario de finales del siglo XIX, sino como una actitud artística que se opone a lo tradicional o academicista. 
hegemónica andina en Colombia (concentrada en su capital: Bogotá), es decir, a la lógica de la "Atenas suramericana" (en cuanto introduce en ella elementos de la cultura popular), utiliza un lenguaje que se aleja de la norma y se niega a ocupar cargos públicos en cualquier estamento oficial.

Por otra parte, la configuración de Macondo como un lugar símbolo y no como una referencia espacial concreta ratifica la toma de posición de García Márquez en contravía del realismo que había imperado en la tradición literaria latinoamericana para dar cuenta de su singularidad cultural $;{ }^{14}$ la toma de posición de García Márquez se puede sintetizar en la frase con la que él mismo definió su estilo en Cien años de soledad: contar lo extraordinario con naturalidad, con la misma "cara de palo" con la que su tía contaba las cosas más extraordinarias y las más espantosas (García Márquez y Vargas Llosa, [1967] s.f.: 16). Para García M., "toda nuestra historia, desde el descubrimiento, se ha distinguido por la dificultad para hacerla creer" (García M., [1979] 1991: 123); por esta razón, Latinoamérica vivía justificándose ante el "Viejo Mundo" (Gutiérrez Girardot, [1993] 1998: 242). El boom de la literatura latinoamericana valida la actitud de "cara de palo" ante nuestra singularidad, nuestro sincretismo, de asumir nuestra historia y nuestra realidad sin buscar la aprobación de otras culturas, y teniendo la seguridad de que, precisamente, esa particularidad era la que aportaba a la cultura universal; ${ }^{15}$ de allí que fuera más importante afianzar una novela hispanoamericana y ya no una novela nacional, como en el siglo XIX y comienzos del XX (Cabrera Infante, [1972] 1991: 140).

Con García Márquez se afirma la novela en Colombia como un género que obtiene lo que se podría denominar como su "mayoría de edad", el derecho a legitimarse como un lenguaje con sus propias reglas: "Hay que hablar de la existencia de un lenguaje de novelista. Cualidad que es importante, sin duda, en un país donde con tanta gratuidad se dan los sucedáneos del género" (Ruiz Gómez, 1965: 470). Las palabras de Ruiz son reveladoras porque, aunque Jaime Mejía Duque afirme que "sigue siendo escandalosa la proporción de libros de versos respecto a los demás en las estadísticas editoriales del país" (Mejía, 1966: 491), el hecho de que aquel hable de la "gratuidad" con que aparecen novelistas verifica una transformación significativa en relación con la situación de este tipo de escritor en épocas anteriores (toda la primera mitad del siglo XX), en las cuales se afirmaba

${ }^{14}$ Hago referencia a toma de posición como a las representaciones discursivas asumidas o defendidas por cada uno de los escritores en sus intervenciones públicas o en sus obras, y a posición como el lugar que ocupa un escritor dentro del campo, según su grado de reconocimiento o legitimación dentro del mismo (Bourdieu, 1997: 308-355).

${ }^{15}$ El viaje de García Márquez a Europa, a finales de la década de 1950, también le comprueba esto y lo ratifica en sus valores costeños y americanos, en su conciencia de pertenecer a una cultura que se había hecho con "los desperdicios del resto del mundo" (García M. citado por Gilard, [1983] 1997: 16-18). 
que nuestra novela estaba en una etapa inicial de desarrollo y que carecíamos de novelistas (Marín, 2013).

El hecho de que sea un novelista el escritor que se convierte en el emblema del creador profesional (García Márquez) no sólo en Colombia sino en todo el continente, hace también que la novela se vuelva un género atractivo para los nuevos escritores y reconocido en el campo literario. De parte de los escritorescreadores, por un lado, se enfatizaba en la necesidad de que el escritor tuviera disciplina, tal como lo demuestra la siguiente afirmación de Álvarez Gardeazábal: "Tengo que ser enfático al afirmar que para ser escritor, antes que facilidad se requieren altas dosis de disciplina. Hay que leer todos los días lo más que se pueda. El escritor debe leer mucho más que el crítico" (Álvarez Gardeazábal entrevistado por Giraldo, 1973: 29). Por otro lado, esta necesidad de disciplina, en el caso de Gabriel García Márquez, se conjuga con la posibilidad de que se reciba por ella una retribución económica correspondiente al trabajo realizado; este autor, entonces, se presenta como el primer escritor-creador colombiano que puede vivir de la escritura de sus obras literarias y que, además, tiene un agente literario. ${ }^{16}$

Tanto García Márquez como Cepeda Samudio habían sido muy enfáticos en negarse a recibir subvenciones o patrocinios tanto del Estado como de la empresa privada, pues para ellos se trataba de formas de compromiso con instancias externas que obstaculizaban el libre trabajo de creación del escritor (Cepeda, [1968] 2001: 157; Cepeda, [1961a] 2001: 169; García M., [1967] s.f.: 30; García M. entrevistado por Angulo, 1962: 3). Esta actitud muestra el cambio que se da frente a los escritores de la primera mitad del siglo XX en Colombia y, en general, en Latinoamérica, quienes se dirigieron

a las autoridades públicas [para reclamar] el mecenazgo estatal, más que privado, el cual a veces se ejerció mediante cargos diplomáticos u oscuros ítems del presupuesto [...]. La literatura como segundo empleo fue la norma de la vida del escritor durante el siglo XX y el hecho de que su primer empleo perteneciera frecuentemente a la órbita estatal, escasamente desligada de la intromisión política partidista, le deparó abundantes vicisitudes [...].

Conquistar la autonomía mediante lo que parecía una libre vinculación profesional con el público consumidor fue entonces su persistente ambición que tomó acentos urgentes cuando se ensanchó el foso entre las doctrinas políticas a que estaban afiliados los escritores y las que regían desde la cúpula del Estado (Rama, 1981: 10-11).

${ }^{16}$ Como ejemplos de escritores "profesionales" en Colombia, en el siglo XX, se pueden mencionar los casos de Germán Arciniegas y Baldomero Sanín Cano; la diferencia con García Márquez reside en que este escritor ha podido vivir de su obra literaria, mientras que aquellos vivieron, sobre todo, de su trabajo en la prensa (al igual que algunos escritores del siglo XIX) y de sus roles como funcionarios públicos. 
La conquista de un público lector-consumidor era la única aceptada por García Márquez, teniendo muy claro que esa conquista no tenía por fin único "mejorar [las] cuentas de banco", sino, sobre todo, "mejorar el mundo" (García M., [1984] 1991: 128). Esta afirmación evidencia el dilema con el que se encontraron los escritores del boom y que tan bien explica Rama en su artículo de 1981: eran escritores para quienes la literatura había llegado a ser su primer empleo; quienes consideraban esta profesión como útil, política, educativa y espiritualmente, como su forma de ejercer su autonomía intelectual; y cuya obra había logrado ser más significativa en cuanto a cantidad y recepción del público que la de sus colegas anteriores. ${ }^{17}$ Sin embargo, estos logros también significaron, a largo plazo, el hecho de convertirse en una especie de "marcas editoriales" que coartó su libertad (Rama, 1981: 11-19) y que se limita aún más en las condiciones actuales del campo literario. A pesar de esto, es claro que para las décadas de 1960 y 1970 fue un proceso necesario para lograr la anhelada profesionalización del escritor.

\section{Conclusión: la literatura, la política, la "moral"}

El escritor poco a poco se separa de las doctrinas políticas oficiales para afirmar su autonomía dentro del campo literario y la capacidad "subversiva" de la literatura. En el caso de Cepeda Samudio, García Márquez y, en general, para el Grupo de Barranquilla, Gilard prueba, por ejemplo, su cercanía al Partido Comunista (Gilard, 1984: 931) y la afiliación y pago de cuotas mensuales a este, por parte de García M., en la década de 1950 (Gilard, [1982] 1997: 58). Después de la Revolución Cubana y en medio de lo que para Colombia significó el Frente Nacional (19581974), momento político e histórico entendido por García Márquez como una "marcha atrás" (Gilard, [1983] 1997: 46), este -y la mayoría de escritores reconocidos del continente- se adhiere al gobierno de Fidel Castro. De esta manera, se legitima, la imagen del escritor latinoamericano como un intelectual comprometido con la cultura y con las transformaciones necesarias para la sociedad latinoamericana; así, la relación entre política y literatura entraba en una nueva fase en América Latina y es claro que "gran parte del reconocimiento de algunos autores latinoamericanos enmarcados en el fenómeno del boom está estrechamente relacionado con el lugar que la Revolución Cubana otorgó al continente" (Chadad, 2006: 212).

${ }^{17}$ De allí también la diferencia en la actitud con la que se refieren al libro: ya no como algo reverencial y erudito sino como objeto de consumo; ahora, es un objeto con el que se "combate" y que resulta atractivo para comprar. El lector se enfrenta al libro en un acto de comunicación directa para confrontar sus verdades y, al mismo tiempo, adquiere un objeto con un valor artístico agregado (García M., [1952d] 1997: 583 -12 de septiembre, El Heraldo-; Rojas H., [1955] 2003: 216 -Diario de Colombia-). 
Este reconocimiento pedía, a cambio, una lealtad a la Revolución y es por eso que el fenómeno conocido como "el caso Padilla" (1971) dividió a los intelectuales latinoamericanos y "produjo una fractura importante" en la "familia intelectual" que se había configurado hasta ese momento y durante toda la década de 1960 (Gilman, 2003: 373) ${ }^{18}$ Cuando se le preguntaba a García Márquez sobre lo sucedido con Padilla, este afirmaba: "Lo que pasa es que cuando los escritores queremos hacer política, en realidad no hacemos política sino moral, y esos dos términos no son siempre compatibles" (García M. [1971] 2003: 260). Para García M. su apoyo al gobierno de Castro no eliminaba su preocupación por la suerte de Padilla; su posición ambigua ante la situación del poeta evidenciaba su necesidad de no sentirse ajeno a los problemas del medio al que pertenecía, pero también de seguir manteniendo su libertad creadora: "El principal deber político de un escritor es escribir bien" (García M., [1967] s.f.: 41). Para él, había una diferencia entre ser escritor y ser intelectual: como intelectual, confiaba en la lucha de la Revolución Cubana y en el gobierno de Fidel Castro, exhibía su militancia política porque sabía que tenía un público sobre el cual ejercer una orientación política, educativa; como escritor, sabía que no podía tener mucha injerencia en los procesos explícitamente políticos de la Revolución y que era mejor que así fuera, si quería conservar su autonomía estética. En el escritor, entonces, la política se entendía como un ethos que permeaba su obra y ayudaba "a que el lector ent[endiera] mejor cuál e[ra] la realidad política y social de su país o de su continente" (García M., [1967] s.f.: 43).

Tres años después, las declaraciones de García Márquez confirmaban lo anterior: "Mi línea es el socialismo por la vía democrática y de unidad de las izquierdas" (García M. entrevistado por Salgar, 1974: 63). A García Márquez le interesaba una versión autónoma del socialismo, no dogmática, y esto le parecía consecuente con su experiencia como colombiano que no había pertenecido a una cuna de élite (Salgar, 1974: 62). Esta posición es la que le permite distanciarse de las prácticas de exclusión y represión de la "Atenas suramericana", configurando una toma de posición distanciada de los partidos políticos oficiales (Liberal y Conservador) y de las tendencias estéticas más reconocidas y aceptadas por la Academia Colombiana de la Lengua y por la élite intelectual bogotana (el regionalismo, el neoclasicismo y el sentimentalismo). Tras la amplia recepción de Cien años de soledad, García Márquez se inserta en un fenómeno literario continental e internacional y valida, así, una nueva manera de comprender la función política del escritor: compromiso político sí, pero sin sacrificar la libertad creadora, la autonomía del arte, ni la autonomía intelectual, la facultad para disentir, para cuestionar lo establecido.

${ }^{18}$ Se trata del encarcelamiento del poeta cubano Heberto Padilla, acusado de traicionar la Revolución, a través de sus libros de poemas y de sus declaraciones. Semanas después, el poeta es liberado y lee un documento en el que, sospechosamente, se arrepiente de sus críticas al gobierno de la Revolución y agradece todo lo que ella ha hecho por él. 
García M., Cepeda y Rojas H. demostraron que el aumento de la autonomía intelectual del escritor permitía una autonomía estética que no era posible mientras los escritores estuvieran apegados a la imagen de la "Atenas suramericana" y todo lo que ella representaba: estar bajo el cobijo del Estado y atender las presiones de la Academia, resguardando la "cultura" en círculos exclusivos que sólo aumentaban la brecha entre las clases populares y las altas. Con su obra, los tres autores ayudaron a hacer conciencia acerca de la necesidad de una transformación en la manera en que se entendían las jerarquías sociales, la literatura, la historia y la realidad del país, tal como quedó registrado en las publicaciones periódicas bogotanas y de la Costa Atlántica en donde estos escritores publicaron sus artículos y parte de su obra literaria; ellos entendieron cómo hacerse parte indispensable del "juego", cómo entrar a hacer parte del campo literario colombiano, cómo aprovechar sus posibilidades para cambiar sus reglas. La actitud de los escritores colombianos ante los poderes oficiales y su grado de conciencia profesional jamás volvió a ser la misma, después de la irrupción de estos escritores caribeños en la mayoritariamente apacible, correcta, "bien" hablada y "educada" vida literaria capitalina.

\section{BIBLIOGRAFÍA}

\section{Fuentes primarias:}

AIRÓ, Clemente.

1962 "Hablemos de novela", Espiral, 84, pp. 7-15.

1965 "El presente de la novela y su desarrollo en Colombia", Espiral, 96, pp. 3-16.

ANGULO, Guillermo.

1962 "Habla el ganador del concurso literario", Lecturas Dominicales, 29 de abril, págs. 1,3 .

CEPEDA SAMUdio, Álvaro.

[1961a] 2001 “Arte subvencionado", en Antología. Bogotá: El Áncora, pp. 167-169.

[1961b] 2001 "Poesía, RIP”, en Antología. Bogotá: El Áncora, pp. 165166.

[1961c] 2001 “Suplementos literarios", en Antología. Bogotá: El Áncora, p. 164.

[1966] 2001 “José Félix Fuenmayor”, en Antología. Bogotá: El Áncora, pp. 162-163.

[1968] 2001 "El sainete anual de novela", en Antología. Bogotá: El Áncora, pp. 157-158.

2001 "Nuestra 'actividad literaria”, en Antología. Bogotá: El Áncora, pp. 153-154. 
FORERO RUIZ, S.J., Carlos.

1950 "El aticismo en la Atenas suramericana", Revista Javeriana, 165, pp. 275-283.

GARCÍA MÁRQUEZ, Gabriel.

1949 "Ceremonia inicial", en Bisswell Cotes, George Lee, Neblina azul. Cartagena: Tipografía Diario de la Costa, pp. 5-7.

[1950] 1997 "El libro de Castro Saavedra", en Obra periodística 1. Textos costeños. Bogotá: Norma, pp. 135-136.

[1951] 1997 "El reportaje de Faulkner", en Obra periodística 1. Textos costeños. Bogotá: Norma, pp. 400-401.

[1952a] 1997 "Hay que tener mala ortografia", en Obra periodística 1. Textos costeños. Bogotá: Norma, pp. 580-581.

[1952b] 1997 "La paz gramatical", en Obra periodística 1. Textos costeños. Bogotá: Norma, pp. 575-576.

[1952c] 1997 "Lugares comunes", en Obra periodística 1. Textos costeños. Bogotá: Norma, pp. 576-577.

[1952d] 1997 Un buen libro por tres razones", en Obra periodística 1. Textos costeños. Bogotá: Norma, pp. 582-583.

[1955] 1997 "El escándalo artístico en Barranquilla. Se prepara demanda del fallo", en Obra periodística 2. Entre cachacos. Bogotá: Norma, pp. 301-305.

[1960a] 1997 "Cuando el país era joven", en Obra periodística 3. De Europa y América. Bogotá: Norma, pp. 568-574.

[1960b] 1997 "La literatura colombiana, un fraude a la nación", en Obra periodística 3. De Europa y América. Bogotá: Norma, pp. 575-579.

[1971] 2003 "Declaraciones de García Márquez a la prensa de Colombia (29 de mayo de 1971)", en Croce, Marcela (comp.), Polémicas intelectuales en América Latina. Del "meridiano intelectual" al caso Padilla (1927-1971). Buenos Aires: Simurg, pp. 259-261.

[1979] 1991 "Fantasía y creación artística en América Latina y el Caribe", en Klahn, Norma y Wilfrido H. Corral (comp.), Los novelistas como críticos, tomo 2. México: Ediciones del NorteFondo de Cultura Económica, pp. 122-128.

[1984] 1991 "Cómo se escribe una novela", en Klahn, Norma y Wilfrido H. Corral (comp.), Los novelistas como críticos, tomo 2. México: Ediciones del Norte-Fondo de Cultura Económica, pp. 128-131.

GARCÍA NIÑO, Guillermo.

1962 "Un filón de la cultura. La Academia Colombiana de la Lengua", Lecturas Dominicales, 28 de octubre, p. 1.

GIRALDO, Hernando.

1973 “Gustavo Álvarez”, Letras Nacionales, 22, pp. 25-31. 
MEJÍA DUQUe, Jaime.

1966 "Evolución del lenguaje poético en Colombia (1896-1966)", Eco, 77 , pp. 468-492.

MELUK, Alfonso.

1952 “Atenas suramericana?”, Sábado, 467, p. 10.

RESTREPO Millán, J. M.

1951 "Qué hay de nuestra famosa tradición humanística?", Suplemento Literario El Tiempo, Bogotá, 22 de abril, p. 1.

ROJAS HERAZO, Héctor.

[1950a] 2003 "Formas o esencias. Polémicas al por menor", en Obra periodística, 1940-1970. Vigilia de las lámparas, tomo 1. Medellín: Universidad EAFIT, pp. 343-344.

[1950b] 2003 "Triunfo y juventud del idioma", en Obra periodística, 1940-1970. Vigilia de las lámparas, tomo 1. Medellín: Universidad EAFIT, pp. 345-349.

[1951a] 2003 "Ausencia y fecundidad de las polémicas", en Obra periodística, 1940-1970. Vigilia de las lámparas, tomo 1. Medellín: Universidad EAFIT, pp. 356-357.

[1951b] 2003 "Explicación de una conducta poética", en Obra periodística, 1940-1970. Vigilia de las lámparas, tomo 1. Medellín: Universidad EAFIT, pp. 350-354.

[1954] 2003 “Todos estábamos esperando", en Obra periodística, 19401970. Vigilia de las lámparas, tomo 1. Medellín: Universidad EAFIT, pp. 175-176.

[1955] 2003 "Breve recado a un lector", en Obra periodística, 19401970. Vigilia de las lámparas, tomo 1. Medellín: Universidad EAFIT, pp. 215-216.

[1956] 2003 "Un hombre entre los ramajes y los días", en Obra periodística, 1940-1970. Vigilia de las lámparas, tomo 1. Medellín: Universidad EAFIT, pp. 248-249.

[1962] 2003 "Pequeño boceto de novela", en Obra periodística, 19401970. Vigilia de las lámparas, tomo 1. Medellín: Universidad EAFIT, pp. 273-275.

RuIz GÓMEZ, Darío.

1965 "El hombre de paja, de Fanny Buitrago-Las bestias de agosto, de Enrique Posada", Eco, 58, pp. 470-472.

SALGAR, José.

1974 “Hacia dónde va Gabo?”, Letras Nacionales, 23, pp. 53-64. 
TÉLLEZ, Hernando.

1951 “¿Pero hay tradición humanística?”, Suplemento Literario El Tiempo, Bogotá, 29 de abril, p. 3.

\section{Fuentes secundarias:}

BOURDIEU, Pierre.

[1992] 1997 Las reglas del arte. Génesis y estructura del campo literario. Barcelona: Anagrama.

CABRERA INFANTE, Guillermo.

[1972] 1991 "Tres tristes tigres, la novela, las novelas", en Klahn, Norma y Wilfrido H. Corral (comp.), Los novelistas como críticos, tomo 2. México: Ediciones del Norte-Fondo de Cultura Económica, pp. 138-142.

CHADAD, Martín.

2006 "Testimonio de partes, o quién es quién", en Croce, Marcela (comp.), Polémicas intelectuales en América Latina. Del "meridiano intelectual" al caso Padilla (1927-1971). Buenos Aires: Simurg, pp. 207-212.

GARCÍA MÁRQUEZ, Gabriel y Mario VARGAS LLOSA.

[1967] s.f. $\quad$ La novela en América Latina: diálogo. Perú: Universidad Nacional de Ingeniería-arlos Milla Batres Ediciones.

GARCÍA USTA, Jorge.

2003 "El poeta como cronista", en Rojas Herazo, Héctor, Obra periodística, 1940-1970. Vigilia de las lámparas, tomo 1. Medellín: Universidad EAFIT, pp. 5-86.

GILARD, Jacques.

[1981] 1997 "Prólogo”, en García Márquez, Gabriel, Obra periodística 1. Textos costeños. Bogotá: Norma, pp. 7-45.

[1982] 1997 "Prólogo", en García Márquez, Gabriel, Obra periodística 2. Entre cachacos, Bogotá, Norma, pp. 7-68.

[1983] 1997 "Prólogo", en García Márquez, Gabriel, Obra periodística 3. De Europa y América, Bogotá, Norma, pp. 7-59.

1984 "El grupo de Barranquilla", Revista Iberoamericana, Pittsburgh, 128-129, pp. 905-935.

GILMAN, Claudia.

2003 Entre la pluma y el fusil. Debates y dilemas del escritor revolucionario en América Latina. Buenos Aires: Siglo XXI Editores.

GUTIÉRREZ GIRARDOT, Rafael.

[1993] 1998 "Mestizaje y cosmopolitismo: perspectivas de interpretaciones literarias y sociológicas en América Latina", en Insistencias. Bogotá: Ariel, pp. 239-256. 
JARAMILLO ZULUAGA, J. Eduardo.

1997 "El arte de la causerie en la Atenas suramericana", El Malpensante, 3, pp. 80-85.

LOAIZA CANO, Gilberto.

1995 Luis Tejada y la lucha por una nueva cultura (Colombia, 18981924). Bogotá: Colcultura-Tercer Mundo.

LÓPEZ, Ricardo.

2011 “Nosotros también somos parte del pueblo': gaitanismo, empleados y la formación histórica de la clase media en Bogotá, 1936-1948", Revista de Estudios Sociales, 41, pp. 84-105.

MARÍN COLORADO, Paula Andrea.

2013 "Revista de las Indias (1936-1951): vehículo de expresión de una conciencia americana", Agenda Cultural Alma Máter, 201, pp. 1618.

Monje Pulido, Camilo Andrés.

2011 Los cafés de Bogotá (1948-1968). Historia de una sociabilidad.

RAMA, Ángel. Bogotá: Editorial Universidad El Rosario.

1981 "Los efectos del boom: mercado literario y narrativa latinoamericana", Punto de Vista, 11, pp. 10-19.

1985 “Autonomía literaria americana", en La crítica de la cultura en América Latina. Barcelona: Biblioteca Ayacucho, pp. 66-81.

ZAMBRANO, Fabio.

2002 "De la Atenas suramericana a la Bogotá moderna. La construcción de la cultura ciudadana en Bogotá", Revista de Estudios Sociales, 11, pp. 916. 